\title{
PERENCANAAN KAWASAN EKO-WISATA TAMAN ASTOR, KABUPATEN BOGOR
}

\author{
Steven ${ }^{1)}$, Suryono Herlambang ${ }^{2)}$, I. G. Oka Sindhu Pribadi ${ }^{3)}$
}

1) Program Studi S1 PWK, Fakultas Teknik, Universitas Tarumanagara, steven0908.ss@gmail.com

2) Program Studi S1 PWK, Fakultas Teknik, Universitas Tarumanagara, s.herlambang@gmail.com

3) Program Studi S1 PWK, Fakultas Teknik, Universitas Tarumanagara, okapribadi@cbn.net

Masuk: 11-08-2020, revisi: 07-09-2020, diterima untuk diterbitkan: 25-09-2020

\begin{abstract}
Abstrak
Perum Perhutani, adalah Badan Usaha Milik Negara (BUMN) yang bertugas mengelola area hutan untuk kepentingan pelestarian dan kemanfaatan umum. Dalam wilayah pengelolaan Perhutani, banyak area yang juga berfungsi sebagai kawasan wisata. Salah satu adalah kawasan wisata Taman Astor yang berada di Kecamatan Tenjo, Kabupaten Bogor, yang saat ini di bawah pengelolaan Perum Perhutani KPH Bogor. Meskipun memiliki potensi wisata yang tinggi, Taman Astor masih sedikit pengunjungnya. Hal ini disebabkan konsep taman wisata yang kurang terarah dan terbatasnya fasilitas penunjang yang disediakan di area tersebut. Untuk meningkatkan kualitas kawasan dan kuantitas pengunjung, studi ini dilakukan dengan berbagai tahapan proses perencanaan: diawali dengan studi komparasi dan analisis SWOT, dilanjutkan dengan rangkaian analisis teknis, seperti: analisis lokasi dan tapak, analisis daya tarik wisata, analisis best practice (studi kasus), analisis kebutuhan ruang, untuk menghasilkan Konsep Pengembangan Wisata Taman Astor dengan konsep Ekowisata. Konsep ini menekankan, selain penambahan atraksi wisata alam dan rekreasi juga memperhatikan prinsip-prinsip konservasi hutan dan pelibatan masyarakat sekitar dalam pemanfaatan dan pengelolaan kawasan.
\end{abstract}

Kata kunci: pemanfaatan lahan Perum Perhutani, konsep eko-wisata, rekreasi alam, pelestarian atau konservasi hutan, pelibatan masyarakat sekitar

\begin{abstract}
Abstrack
Perum Perhutani, is a State-Owned Enterprise in charge of managing forest areas for the benefit of preservation and public benefit. Within the Perhutani management area, many areas also function as tourist areas. One of them is the Taman Astor tourist area in Tenjo District, Bogor Regency, which is currently under the management of Perum Perhutani KPH Bogor. Even though it has high tourism potential, Taman Astor still has few visitors. This is due to the concept of a tourist park that is less focused and the supporting facilities provided in the area are limited. To improve the quality of the area and the quantity of visitors, this study is carried out in various stages of the planning process: starting with a comparative study and SWOT analysis, followed by a series of technical analyzes, such as: site and place analysis, analysis of tourist attractions, analysis of best practice (case study), space requirements analysis, to produce the Taman Astor Tourism Development Concept with the Ecotourism concept. This concept emphasizes, in addition to adding natural and recreational tourism attractions, it also pays attention to the principles of forest conservation and the involvement of the surrounding community in the use and management of the area.
\end{abstract}

Keywords: land use of Perum Perhutani, the concept of eco-tourism, nature recreation, forest preservation atau conservation, involvement of the surrounding community 


\section{PENDAHULUAN}

\section{Latar Belakang}

Indonesia merupakan kawasan yang memiliki ragam jenis kepariwisataan seperti danau, pantai, gunung, hutan, taman dan sejenisnya. Seiring perkembangan waktu, Kawasan wisata di Indonesia mulai diperhatikan pihak pemerintah untuk dilakukan penataan fisik agar dapat menunjang kawasan wisata tersebut.

Suatu kawasan wisata harus memiliki daya Tarik yang dapat diberikan untuk pengunjung. Kawasan wisata umumnya memiliki sumber daya dan modal yang perlu dimanfaatkan secara optimal yang ditujukan untuk meningkatkan pendapatan nasional, memperluas dan memeratakan kesempatan berusaha dan lapangan kerja, mendorong pembangunan daerah, memperkenalkan dan mendayagunakan daya tarik wisata dan destinasi di Indonesia.

Salah satu Kawasan yang memiliki potensi pariwisata berada di Kabupaten Bogor. Kabupaten Bogor memiliki suatu dinas yang mengawasi, menata, dan mengembangkan Kawasan wisata di kabupaten Bogor sendiri yaitu Perhutani Kesatuan Pemangkuan Hutan (KPH) Kabupaten Bogor.

Berdasarkan hasil wawancara dengan Perhutani Kabupaten Bogor sebagai pemegang hak kawasan wisata, terdapat 22 kawasan wisata yang menjadi fokus penataan sehingga dapat berkembang sebagai Kawasan wisata baru. Salah satunya adalah Taman Astor yang berada di Kecamatan Tenjo. Akan tetapi rata rata pengunjung perminggunya adalah 50 orang sehingga terlihat jarang pengunjung. Hal ini mungkin disebabkan masih kurangnya fasilitas penunjang Kawasan wisata tersebut. Selain itu juga tidak adanya konsep yang dapat menunjang Kawasan wisata tersebut Sehingga membuat Kawasan wisata ini menjadi tidak terarah.

\section{Rumusan Permasalahan}

Sampai saat ini Kawasan Taman Astor ini tidak maksimal dalam mengembangkan kawasan wisata seluas 4,09 Ha dikarenakan terdapat lahan yang belum dikembangkan seluas 1,1 ha serta tidak adanya rencana induk atau masterplan ataupun denah wisata sehingga pengunjung cukup sulit mengerti daya tarik wisata yang ditawarkan.

\section{Tujuan}

Penulis memiliki 3 Tujuan dalam studi ini yaitu mencari daya Tarik Kawasan wisata yang dapat memberikan nilai lebih, membuat konsep kawasan wisata dan membuat Masterplan Taman Astor

\section{KAJIAN LITERATUR}

\section{Pengertian Pariwisata}

Pengertian pariwisata menurut Norval dalam (Muljadi dan Nurhayati, 2002) adalah keseluruhan kegiatan yang berhubungan dengan masuk, tinggal, dan pergerakan penduduk asing di dalam atau di luar suatu negara, kota, atau wilayah tertentu. Menurut definisi yang lebih luas yang dikemukakan oleh (Kodhyat, 1983) pariwisata adalah perjalanan dari satu tempat ke tempat lain bersifat sementara, dilakukan perorangan atau kelompok, sebagai usaha mencari keseimbangan dan kebahagiaan dengan lingkungan hidup dalam dimensi sosial, budaya, alam, dan ilmu. Selanjutnya menurut (Musanef, 1995), mengartikan pariwisata sebagai suatu perjalanan yang dilaksanakan untuk sementara waktu, yang dilakukan dari satu tempat ke tempat yang lain untuk menikmati perjalanan bertamasya dan berekreasi.

\section{Pengertian Pengunjung}

Pengunjung adalah orang yang melakukan perjalanan jauh meninggalkan rumahnya untuk keperluan bisnis, bersenang-senang, mengunjungi teman dan saudara atau untuk alasan lainnya. Pengunjung yang tinggal bermalam disebut tourists (wisatawan) sedangkan pengunjung 
yang tidak tinggal lebih dari satu malam disebut sebagai same-day visitor (pengunjung harian).

\section{Zonasi Wisata}

Menurut (Gunn, 1972), sebuah kawasan wisata sebaiknya ditata dan didesain dengan memperhatikan 3 unsur yaitu:

a. Zona Inti

Zona inti ini merupakan komponen utama (main attraction) dalam sebuah atraksi wisata disuatu tempat yang dilengkapi dengan fasilitas pendukung

b. Zona Penyangga

Zona Penyangga ini berada di sekitar zona inti yang memisahkan antara zona inti (main attraction) dengan zona pemanfaatan/zona pelayanan

c. Zona Pelayanan

Zona ini merupakan suatu zona yang diperuntukan bagi penyiapan pelayanan dimana seluruh fasilitas dan aktivitas dikelompokan untuk wisatawan yang merupakan zona akhir transportasi serta adanya pelayanan seperti akomodasi restoran dan sejenisnya

\section{Pengertian Masterplan}

Master Plan merupakan kerangka dari semua rencana pembangunan gedung dan infrastruktur di suatu kawasan atau wilayah. Master Plan secara harfiah diterjemahkan sebagai Rencana Induk dan berisi tentang semua perencananan pembangunan yang menyeluruh (komprehensif) dan terpadu (integratif)

\section{Metode}

Metode Penelitian pada dasarnya merupakan cara ilmiah untuk mendapatkan data dengan tujuan dan kegunaan tertentu. Dalam hal ini, banyak sumber yang penulis gunakan antara lain dari BPS Kabupaten Bogor, Perhutani Kabupaten Bogor dan Survei Lapangan. Dalam proses pembuatan laporan ini, metode penelitian yang digunakan adalah mengumpulkan dan menganalisis data yang diperoleh dari studi literatur, observasi lapangan dan wawancara. Metode penelitian ini digunakan untuk menentukan Perencanaan pada Kawasan wisata Taman Astor

\section{Jenis Penelitian}

Dalam mencari konsep pengembangan yang tepat, maka penulis akan memakai jenis penelitian deskriptif dan penelitian lapangan. Penelitian deskriptif merupakan suatu penelitian yang bertujuan membuat gambaran secara sistematis dan akurat mengenai fakta-fakta dalam objek penelitian penulis. Sedangkan Penelitian Lapangan merupakan suatu penelitian secara intensif tentang latar belakang keadaan, serta interaksi lingkungan baik individu, kelompok Lembaga atau masyarakat. Dalam hal ini penulis akan mencari daya tarik utama Kawasan wisata Taman Astor ini dengan Penelitan Lapangan. Akan tetapi dalam masa Pandemi Covid-19 ini Penelitian Lapangan akan terbatas. Beruntungnya sebelum terjadinya Pandemi ini penulis sudah melakukan survey sebanyak 3 kali dan diharapkan dapat mewakili seluruh data yang penulis dapatkan.

\section{Lokasi dan Waktu Penelitian}

Lokasi dan waktu penelitian ini berguna untuk mengetahui batasan waktu dan tempat pada objek studi penulis. Objek Penelitian yang penulis teliti yaitu kawasan wisata Taman Astor yang berada di Kecamatan Tenjo, Kabupaten Bogor. Dengan waktu penelitian hari biasa dan hari libur. Pada pencarian batas Kawasan Taman Astor, penulis tidak mendapatkan batas pasti sehingga penulis melakukan pengindraan jarak dekat dengan mengunakan aplikasi GPS Essentials sehingga didapat batas sebagai berikut 


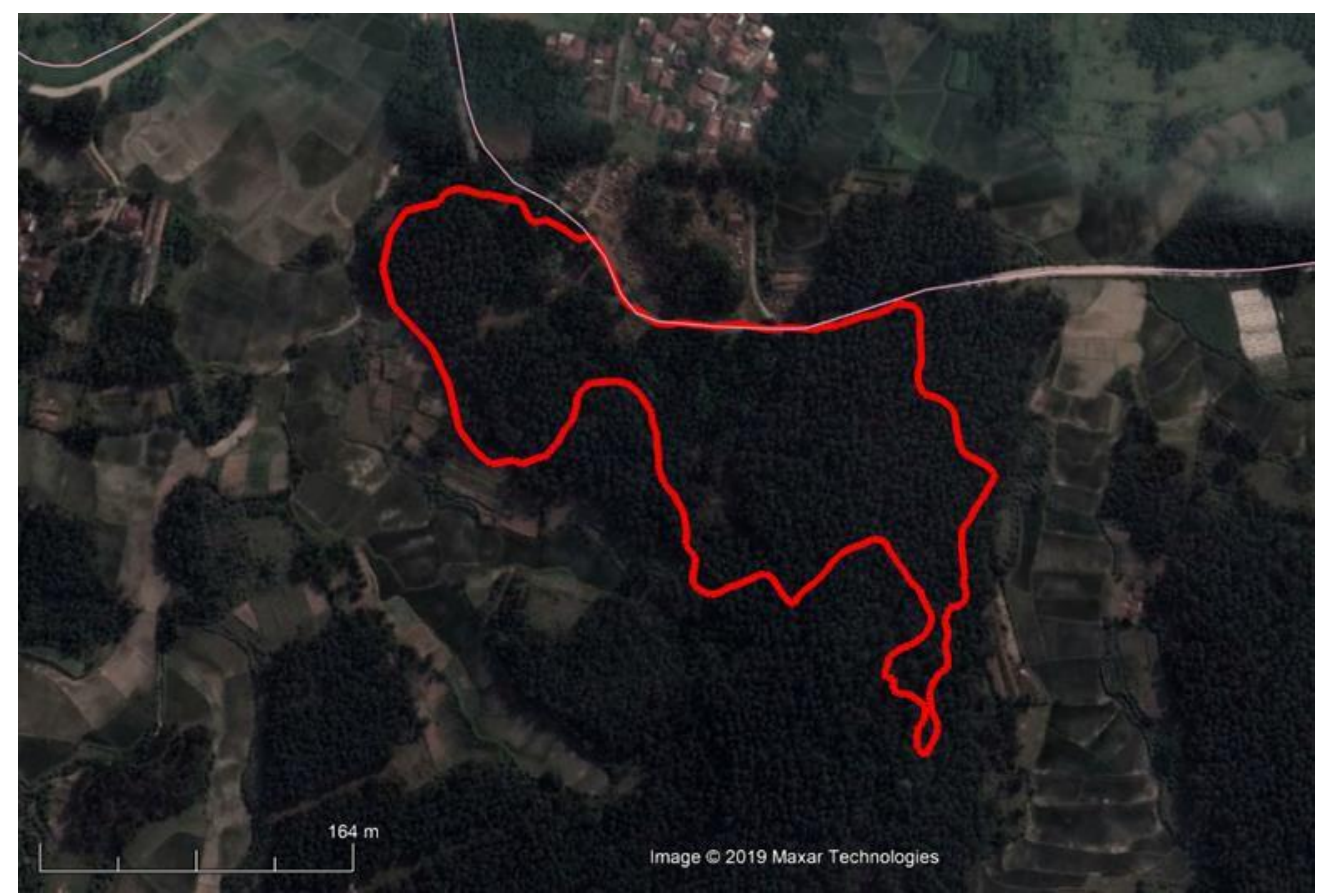

Gambar 1. Batas Taman Astor

Sumber: Pengindraan dekat dengan GPS Essentials, 2019

\section{Teknik Pengumpulan Data}

Penulis akan mencari data sesuai dengan kebutuhan penulis dengan mencari data Primer dan data Sekunder. Data Primer akan terbagi menjadi 2 yaitu Observasi Lapangan dan Wawancara. Penulis sudah membuat desain wawancara untuk pengelola Taman Astor. Berikut adalah desain wawancara yang penulis buat:

Tabel 1.Desain Wawancara Kawasan Taman Astor

\begin{tabular}{|c|c|c|c|}
\hline No & Komponen & Tujuan & Pertanyaan \\
\hline \multirow{7}{*}{1} & \multirow{7}{*}{$\begin{array}{l}\text { Profil umum dan } \\
\text { Sejarah Taman Astor }\end{array}$} & \multirow{7}{*}{$\begin{array}{l}\text { Untuk mengetahui profil } \\
\text { Kawasan Wisata Taman Astor }\end{array}$} & Tahun Operasional \\
\hline & & & Tujuan Operasional \\
\hline & & & Pihak yang bertanggung jawab \\
\hline & & & Kondisi sekitar Taman Astor \\
\hline & & & $\begin{array}{c}\text { Rencana Pengembangan } \\
\text { kedepannya }\end{array}$ \\
\hline & & & Pendapatan Taman Astor \\
\hline & & & Fasilitas yang tersedia \\
\hline
\end{tabular}

Sumber: Hasil Olahan Penulis, 2019 
Data Sekunder akan terbagi menjadi 2 yaitu Studi Literatur dan Data Instansi. Berikut adalah Tabel kebutuhan data penelitian:

Tabel 2. Kebutuhan Data Penelitian

\begin{tabular}{|c|c|c|c|c|c|c|}
\hline \multirow{2}{*}{ No } & \multirow{2}{*}{ Jenis Data } & \multirow{2}{*}{ Bentuk Data } & \multirow{2}{*}{ Sumber Data } & \multirow{2}{*}{ Periode } & \multicolumn{2}{|c|}{ Jenis Data } \\
\hline & & & & & Kualitatif & Kuantitatif \\
\hline \multirow{4}{*}{1} & & & Fisik Dasar Kawasan & & & \\
\hline & $\begin{array}{c}\text { Batas } \\
\text { Administrasi }\end{array}$ & Peta & Kabupaten Bogor & & $v$ & \\
\hline & $\begin{array}{l}\text { Pembagian } \\
\text { Wilayah Per } \\
\text { Kecamatan }\end{array}$ & $\begin{array}{l}\text { Peta, dan } \\
\text { Tabel }\end{array}$ & $\begin{array}{l}\text { BPS Pemerintah Kabupaten } \\
\text { Bogor }\end{array}$ & Eksisting & $v$ & $\mathrm{v}$ \\
\hline & $\begin{array}{l}\text { Curah Hujan } \\
\text { dan Iklim }\end{array}$ & Kuantitatif & $\begin{array}{c}\text { BPS Pemerintah Kabupaten } \\
\text { Bogor }\end{array}$ & Eksisting & & v \\
\hline \multirow{3}{*}{2} & & & Kependudukan & & & \\
\hline & $\begin{array}{l}\text { Data Jumlah } \\
\text { Penduduk }\end{array}$ & Kuantitatif & $\begin{array}{c}\text { BPS Pemerintah Kabupaten } \\
\text { Bogor }\end{array}$ & Eksisting & & v \\
\hline & $\begin{array}{l}\text { Pertumbuhan } \\
\text { Penduduk }\end{array}$ & Kuantitatif & $\begin{array}{c}\text { BPS Pemerintah Kabupaten } \\
\text { Bogor }\end{array}$ & Eksisting & & v \\
\hline \multirow[b]{2}{*}{3} & & & Perhutani KPH Bogor & & & \\
\hline & $\begin{array}{c}\text { Persebaran } \\
\text { Kawasan } \\
\text { Wisata } \\
\text { Perhutani } \\
\text { KPH Bogor }\end{array}$ & Peta & Perhutani KPH Bogor & Eksisting & $v$ & \\
\hline \multirow{3}{*}{4} & $\begin{array}{l}\text { Batas Objek } \\
\text { Studi }\end{array}$ & Peta & $\begin{array}{l}\text { Kawasan Objek Studi } \\
\text { Perhutani KPH Bogor }\end{array}$ & Eksisting & $v$ & \\
\hline & Sarana & Peta dan Tabel & Survei Lapangan & Eksisting & v & V \\
\hline & Prasarana & Peta dan Tabel & Survei Lapangan & Eksisting & v & V \\
\hline
\end{tabular}

Sumber: Hasil Olahan Penulis, 2019

\section{Analisis}

Analisis Lokasi dan Tapak

Analisis lokasi dan tapak ini dilakukan dengan tujuan mengetahui karakteristik, potensi dan masalah yang berada di Wisata Taman Astor, sehingga dapat dilakukannya strategi untuk pengusulan konsep wisata yang tepat pada Kawasan Wisata Taman Astor.

Analisis Daya Tarik Wisata

Analisis daya tarik ini dilakukan untuk mengatahui daya tarik dari Wisata Taman Astor dan kegiatan wisata yang membuat wisatawan ingin berkunjung ke Kawasan Wisata Taman Astor.

Analisis Best Practice

Analisis Best Practice ini berguna untuk menambahkan kegiatan wisata agar sesuai kondisi Taman Astor dengan melihat kondisi wisata sejenis. Wisata sejenis yang penulis pilih adalah Grafika Cikole dikarenakan mengunakan suasana hutan sebagai daya tariknya. 
Analisis Konsep Pengembangan Wisata

Analisis Konsep Wisata bertujuan untuk menentukan konsep pengembangan wisata yang sesuai untuk Wisata Taman Astor yang sesuai dengan potensi dan masalah yang terdapat di Wisata Taman Astor, serta membuat Masterplan yang sesuai dengan konsep yang ditentukan.

Analisis Kebutuhan Ruang

Analisis kebutuhan ruang ini dilakukan untuk melakakukan identifikasi ruang yang akan dijadikan kegiatan wisata di Taman Astor.

\section{Alat Analisis}

Analisis SWOT

Pengertian SWOT terbagi menjadi 4 yaitu Strength (Kekuatan), untuk mengetahui kekuatan objek studi dari dalam kawasan, Weakness (Kelemahan), untuk mengetahui kelemahan dari dalam kawasan, Opportunity (Peluang), untuk mengetahui peluang yang muncul dari luar dan Threats (Ancaman), untuk mengetahui Ancaman yang ditimbulkan terutama dari segi keuangan.

Analisis Komparasi

Teknik analisis komparasi yang akan digunakan adalah Teknik Lexicographic Ordering yang berisi Alternatif yang diranking berdasarkan kriteria yang paling penting, kedua paling penting hingga terpilih alternatif dengan ranking paling tinggi.

\section{Waktu Penelitian}

Penelitian pada awalnya akan dilakukan dalam waktu 4 bulan yang dimulai dari bulan Agustus 2019 hingga bulan Juli 2020. Akan tetapi dikarenakan pandemic virus Covid-19 menyebabkan perubahan dalam jadwal penelitian. Hasil observasi menjadi tidak rutin dan dirubah menjadi observasi pengindraan jauh dengan mengunakan media online menjadikan penelitan ini menggunakan hasil observasi yang sudah didapat sebelum pandemi untuk dipakai lebih lanjut.

\section{DISKUSI DAN HASIL}

Taman Astor berada pada Kecamatan Tenjo. Taman Astor sendiri dikelola oleh KPH Perhutani Bogor. Berikut adalah peta pesebaran kawasan wisata yang dikerjasamakan Perhutani:
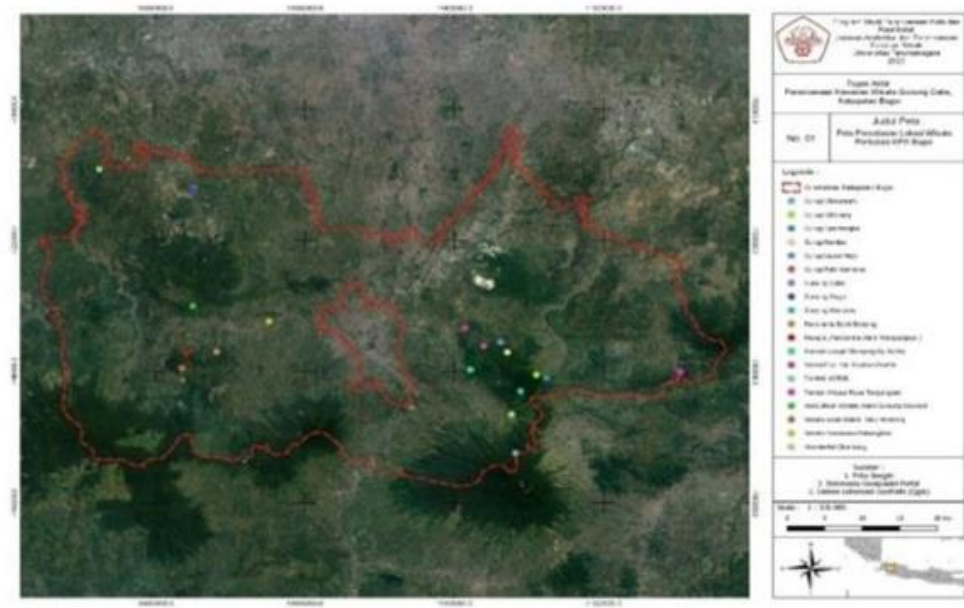

Gambar 2. Peta Kawasan Wisata Kerjasama KPH

Perhutani Bogor

Sumber: Hasil Olahan Penulis, 2019 
Taman Astor memiliki topografi yang cenderung datar dengan luas 4,09 ha. Pada kondisi Eksisting, Area Taman Astor sudah memiliki Sarana Kawasan wisata antara lain Loket Tiket, Saung untuk beribadah, Kantor Sekretariat, Warung, Toilet dan lain sebagainya

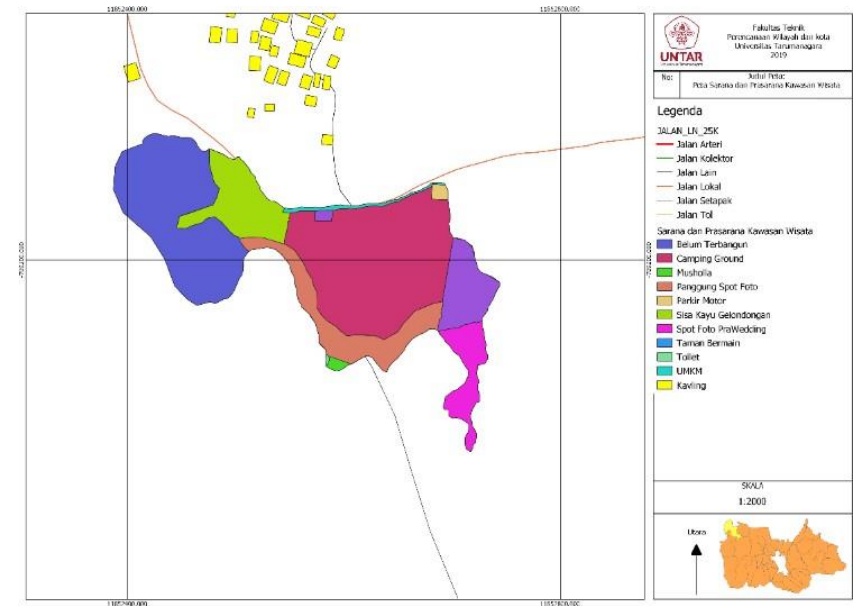

Gambar 3. Peta Sarana Kawasan Wisata Taman Astor Sumber: Hasil Olahan Penulis, 2019

Secara singkat Taman Astor pada awalnya merupakan hutan produksi yaitu hutan akasia. Penduduk setempat juga ingin menggunakan lahan tersebut selain hutan produksi. Saat ini, kawasan tersebut digunakan sebagai Kawasan wisata karena ingin memberdayakan jenis usaha mikro kecil menengah. (UMKM). Taman Astor sendiri ditetapkan sebagai Kawasan wisata pada bulan Maret 2017. Dengan Perjanjian Kerja Sama (PKS) dengan LMDH yang berisi masyarakat sekitar kelurahan Tenjo yang ingin memajukan daerah tersebut. Hal ini juga didukung dengan BUMdes Desa Babakan yang ingin penggunaaan dana desa difokuskan pada kepariwisataan. Taman Astor sendiri secara hukum sudah dinyatakan dalam Surat Kadivre tanggal 4 Mei 2018 mengenai penunjukan lokasi wisata.

\section{Analisis}

Analisis Lokasi dan Tapak

Aksesibitas Taman Astor terbagi menjadi 5 Wilayah yaitu dari Jakarta, Kota Tangerang, Kabupaten Tangerang, Tangerang Selatan dan Kota Tangerang menuju Taman Astor. Berikut adalah Tabel Jarak Tempuh menuju Taman Astor:

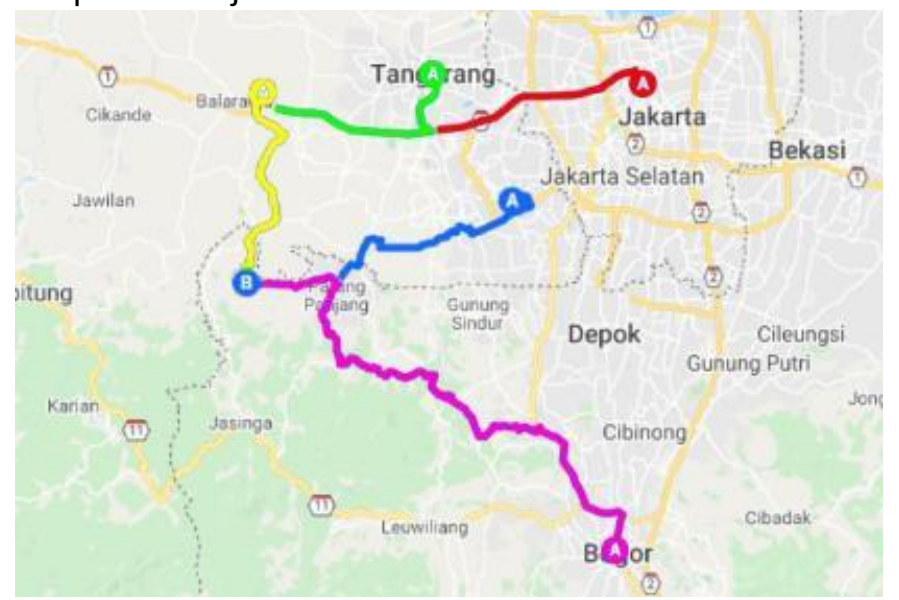

Gambar 4. Aksesibilitas menuju Taman Astor Sumber: My Maps, 2020

Tabel 3. Jarak Tempuh menuju Taman Astor

No Nama Daerah Daerah Tujuan Jarak (Km) Waktu (Jam - Menit)




\begin{tabular}{lllcc}
\hline 1 & Jakarta & Taman Astor & $65,6 \mathrm{~km}$ & 1 jam 20 menit \\
\hline 2 & Kota Tangerang & Taman Astor & $35,7 \mathrm{~km}$ & 1 jam 15 menit \\
\hline 3 & Kabupaten Tangerang & Taman Astor & $27,5 \mathrm{~km}$ & 59 menit \\
\hline 4 & Tangerang Selatan & Taman Astor & $45,5 \mathrm{~km}$ & 1 jam 13 menit \\
\hline 5 & Kota Bogor & Taman Astor & $72,4 \mathrm{~km}$ & 1 jam 54 menit \\
\hline
\end{tabular}

Sumber: Google Maps, 2020

Dari seluruh daerah asal yang ada, Kabupaten Tangerang merupakan daerah Asal terdekat. Batas Kabupaten Tangerang memang sangat dekat dengan Kawasan Wisata Taman Astor itu sendiri. Untuk kendaraan Umum sendiri Kawasan ini tidak dilewati oleh moda transportasi umum seperti bus kecil maupun bus besar sehingga disarankan untuk membawa kendaraan pribadi guna mempermudah berpergian ke Taman Astor.

Luas Total Kawasan Taman Astor adalah 4.09 ha (berdasarkan hasil pengindraan langsung dengan GPS Essential). Berikut adalah batas - batas lokasi dari Kawasan Taman Astor.

Batas Utara : Jalan Raya Manunggal XIX dan Pemukiman warga sekitar Batas Barat : Perkebunan Singkong

Batas Selatan : Kawasan Hutan Produksi Tetap Batas Timur : Perkebunan Singkong.

Untuk Kondisi Sarana Prasarana di Taman Astor akan dijelaskan dalam tabel berikut:

Tabel 4. Sarana dan Prasarana Pendamping

\begin{tabular}{|c|c|}
\hline Sarana & Kondisi \\
\hline Camping Ground & $\begin{array}{l}\text { Semi / Tidak Permanen } \\
\text { Memadai } \\
\text { Baik }\end{array}$ \\
\hline Musholla & $\begin{array}{l}\text { Permanen } \\
\text { Memadai } \\
\text { Baik }\end{array}$ \\
\hline Panggung Spot Foto & $\begin{array}{l}\text { Semi } \\
\text { Permanen } \\
\text { Memadai } \\
\text { Kurang Baik }\end{array}$ \\
\hline Parkir Motor & $\begin{array}{l}\text { Permanen } \\
\text { Kurang } \\
\text { Memadai } \\
\text { Baik } \\
\end{array}$ \\
\hline Parkir Sepeda & $\begin{array}{l}\text { Permanen } \\
\text { Memadai } \\
\text { Baik }\end{array}$ \\
\hline Sisa Kayu Gelondongan & $\begin{array}{l}\text { Semi Permanen } \\
\text { Sangat } \\
\text { Memadai } \\
\text { Baik } \\
\end{array}$ \\
\hline Spot Foto Prawedding & $\begin{array}{l}\text { Permanen } \\
\text { Memadai } \\
\text { Baik }\end{array}$ \\
\hline Toilet & $\begin{array}{l}\text { Permanen } \\
\text { Kurang } \\
\text { Memadai } \\
\text { Kurang Baik }\end{array}$ \\
\hline UMKM & $\begin{array}{l}\text { Semi } \\
\text { Permanen } \\
\text { Memadai } \\
\text { Baik }\end{array}$ \\
\hline
\end{tabular}




\begin{tabular}{ll}
\hline Tempat bermain Anak & $\begin{array}{l}\text { Permanen } \\
\text { Memadai } \\
\text { Baik }\end{array}$ \\
\hline Belum Terbangun & Permanen \\
\hline Utilitas & Kondisi \\
\hline Air Bersih & Kurang Memadai \\
\hline Persampahan & Kurang Memadai \\
\hline Jaringan Listrik & Kurang Memadai \\
\hline Jaringan Telekomunikasi & Kurang Memadai \\
\hline Sumber : Olahan Penulis, 2020
\end{tabular}

Sumber : Olahan Penulis, 2020

Analisis SWOT

Analisis ini berguna untuk menjabarkan apa yang harus dilakukan guna memanfaatkan kekuatan dan kesempatan yang ada serta menghindari ancaman yang dapat terjadi. Berikut adalah SWOT dari Kawasan Taman Astor.

Tabel 5. SWOT Taman Astor

\begin{tabular}{|c|c|c|}
\hline & Strenght (S) & Weakness (W) \\
\hline & $\begin{array}{l}\text { - } \text { Kontur lahan baik } \\
\text { - } \text { Adanya kayu yang dapat } \\
\text { digunakan } \\
\text { - Panorama yang asri }\end{array}$ & $\begin{array}{l}\text { - Jaringan Listrik dan Air yang } \\
\text { masih kurang } \\
\text { - Penampungan Sampah yang } \\
\text { masih kurang } \\
\text { - Lahan parkir yang kurang }\end{array}$ \\
\hline Opportunity (O) & $\mathrm{S}-\mathrm{O}$ & W-O \\
\hline $\begin{array}{l}\text { - Adanya Lahan yang belum } \\
\text { dikembangkan } \\
\text { - Daerah Kecamatan Tenjo } \\
\text { ingin mengunakan dana } \\
\text { BUMdes nya untuk } \\
\text { pengembangan Pariwisata }\end{array}$ & $\begin{array}{l}\text { - Pengunaan kayu yang baik } \\
\text { untuk menambah kegiatan } \\
\text { wisata atau peningkatan } \\
\text { wisata dengan bantuan } \\
\text { dana BUMdes } \\
\text { - Membuat kegiatan wisata } \\
\text { yang memanfaatkan kondisi } \\
\text { alam }\end{array}$ & $\begin{array}{l}\text { - Mengembangkan Lahan Parkir } \\
\text { - Memastikan adanya distribusi } \\
\text { air dan lisrik serta sistem } \\
\text { persampahan di Taman Astor }\end{array}$ \\
\hline Threat $(\mathrm{T})$ & S-T & W-T \\
\hline $\begin{array}{l}\text { - Munculnya Wisata serupa } \\
\text { di Kecamatan Tenjo }\end{array}$ & $\begin{array}{l}\text { Memberikan value added dan } \\
\text { unique selling point di dalam } \\
\text { kawasan yang akan } \\
\text { dikembangkan }\end{array}$ & $\begin{array}{l}\text { - Menonjolkan kondisi alam } \\
\text { Taman Astor sebagai salah satu } \\
\text { unique selling point }\end{array}$ \\
\hline
\end{tabular}

Sumber : Olahan Penulis, 2020

Dalam Analisis Lokasi dan Tapak diketahui bahwa Taman Astor berada pada Kabupaten Bogor. Daerah Asal terdekat menuju Taman Astor selain Kabupaten Bogor adalah Kabupaten Tanggerang. Pengadaan fasilitas Taman Astor sendiri sudah cukup memadai akan tetapi masih terdapat fasilitas dalam kondisi kurang baik seperti Pangung Spot Foto dan Toilet. Dalam Analisis SWOT Taman Astor harus mengunakan sumber daya alam yang tersedia dan menonjolkan kondisi alam sebagai salah satu unique selling point.

Analisis Daya Tarik

Analisis ini bertujuan untuk mengetahui potensi kegiatan wisata yang dapat dilakukan di Kawasan Wisata Taman Astor.Berikut adalah jenis-jenis kegiatan wisata yang dapat dilakukan di Kawasan Taman Astor. 
Tabel 6. Daya Tarik Wisata di Kawasan Wisata Taman Astor

\begin{tabular}{lll}
\hline No & Jenis Kegiatan & Keterangan \\
\hline 1. & Menikmati & Hutan yang berada di Taman Astor memiliki pemandangan yang \\
& $\begin{array}{l}\text { asri sehingga sangat sejuk. Dalam Kawasan inipun sudah mulai } \\
\text { ramai foto } \text { pre-wedding dikarenakan sangat asri dan indah serta } \\
\text { disediakannya_panggung foto }\end{array}$
\end{tabular}

\begin{tabular}{ll}
\hline 2. Camping Ground & Dalam_Kawasan ini juga terdapat Camping Ground yang \\
& biasanya digunakan untuk berkemah di daerah hutan oleh \\
(umumnya) Anak Muda yang ingin berkemah dan untuk media \\
campingnya_mengunakan tenda.
\end{tabular}

3. Motocross Dalam Taman Astor terdapat jalur Motocross yang jalurnya sudah terbentuk dikarenakan banyaknya Kendaraan yang melalui ialur tersebut.

\begin{tabular}{lll}
\hline 4. Taman Bermain Anak & $\begin{array}{l}\text { Dalam Taman Astor sendiri juga terdapat Taman Bermain Anak } \\
\text { yang berisi Ayunan, Jungkat Jungkit, dan Perosotan. }\end{array}$ \\
\hline
\end{tabular}

Sumber : Olahan Penulis, 2020

Berdasarkan Tabel diatas penulis merasa bahwa Kawasan wisata ini masih cukup kurang dalam menyediakan atraksi wisata sehingga penulis ingin menambahkan kegiatan wisata tambahan yang dapat melengkapi kegiatan wisata lainnya. Berikut adalah rekomendasi kegiatan wisata di Kawasan Wisata Taman Astor.

Tabel 7. Rekomendasi Kegiatan Wisata

\begin{tabular}{|c|c|c|}
\hline No & Kegiatan & Usulan \\
\hline 1 & Glamping & $\begin{array}{l}\text { Pembuatan Tempat Camping yang mengunakan bahan bahan yang } \\
\text { berkualitas seperti kayu atau kain yang tebal dan cukup luas sehingga } \\
\text { terasa sangat nyaman } \\
\text { untuk ditempati }\end{array}$ \\
\hline 2. & PaintBall & $\begin{array}{l}\text { Penyediaan Kegiatan Wisata seperti Paintball akan membuat Kawasan Taman } \\
\text { Astor akan menjadi lebih menarik. Untuk arena dan peralatannya cukup } \\
\text { ringan sehingga } \\
\text { hanya perlu untuk membuat rintangan atautempat perlindungan }\end{array}$ \\
\hline
\end{tabular}

Sumber : Olahan Penulis, 2020

Analisis Konsep Perencanaan

Analisis ini bertujuan untuk menentukan konsep-konsep yang sesuai dengan perencanaan yang akan dilakukan terhadap Taman Astor. Kriteria Kriteria yang akan diuji adalah Daya Tarik, Kondisi Alam, Atraksi, dan Nilai. Berikut adalah Tabel Kriteria Konsep Kawasan Wisata.

Tabel 8. Kriteria Konsep Kawasan Wisata

\begin{tabular}{llll}
\hline Kriteria & Ekowisata & Geowisata & Agrowisata \\
\hline Daya Tarik & Alam & $\begin{array}{l}\text { Ketinggian / Bentang } \\
\text { Alam }\end{array}$ & Alam \\
\hline Kondisi Alam & Hutan & Tebing & Pertanian \\
\hline Atraksi & Pelestarian & View & Budidaya \\
\hline Aspek & Konservasi & Edukasi & \\
\hline
\end{tabular}

Sumber : Olahan Penulis, 2020 
Tabel 9. Lexicographic Ordering

\begin{tabular}{|c|c|c|c|c|}
\hline Konsep & Daya Tarik & Kondisi Alam & Atraksi & Aspek \\
\hline \multicolumn{5}{|l|}{ Ekowisata } \\
\hline \multicolumn{5}{|l|}{ Geowisata } \\
\hline \multicolumn{5}{|l|}{ Agrowisata } \\
\hline \multicolumn{5}{|c|}{ Terpilih } \\
\hline \multicolumn{5}{|c|}{ Bisa Direncanakan } \\
\hline & & ilih & & \\
\hline
\end{tabular}

Sumber : Olahan Penulis, 2020

Dengan hasil Lexicographic Ordering dapat disimpulkan bahwa perencanaan konsep Taman Astor akan mengarah kepada Agrowisata sehingga akan ada pengembangan budidaya tanaman yang dapat diproduksi sehingga dapat dimanfaatkan masyarakat sekitar. Akan tetapi dalam hal ini Kawasan Taman Astor lebih cocok dengan Ekowisata dikarenakan kondisi Eksiting lebih mendukung sehingga Ekowisata akan terpilih menjadi konsep kawasan wisata dan konsep Agrowisata dapat mengunakan Kebun Singkong warga yang berada di sekitar Taman Astor .

\section{Analisis Best Practice}

Analisis Best Practice bertujuan untuk mengetahui karakteristik yang mendekati dengan kondisi eksisting Taman Astor dari segi fasilitas dan prasarana yang mendukung Kawasan pariwisata. Objek wisata yang dijadikan benchmarking adalah Grafika Cikole.

Grafika Cikole merupakan Kawasan wisata di Kabupaten Bandung Selatan yang memiliki luas 9 ha dengan ketinggian 1400 meter diatas permukaan laut dan terdapat banyak fasilitas dan memiliki tujuan utama sebagai wadah atau memfasilitasi masyarakat yang ingin menyelenggarakan aktivitas luar ruangan khususnya bagi perusahaan, instansi, sekolah dan sebagai tempat wisata keluarga.

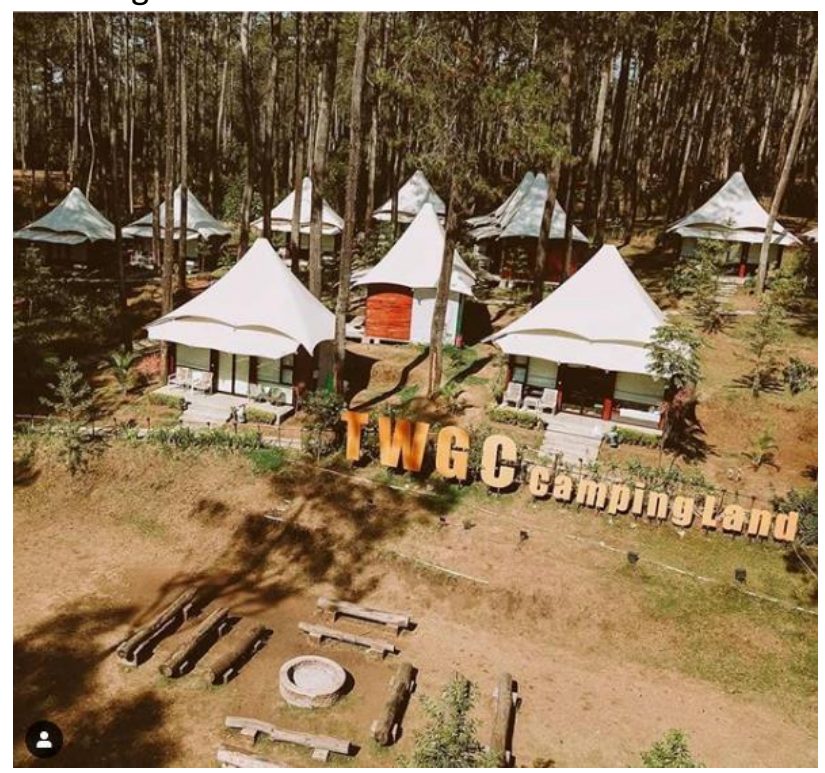

Gambar 5. Kawasan Camping Grafika Cikole

Sumber: Instagram @officialgrafika, 2020

Grafika Cikole sendiri masih terdapat kekurangan dan kelebihan dalam memenuhi prinsip ekowisata. Berdasarkan kondisi eksisting pada Grafika Cikole maka prinsip ekowisata yang dapat diterapkan adalah:

1. Pada kriteria Konservasi yaitu fasilitas pendukung yang dibangun tidak merusak lingkungan dan disesuaikan dengan karakteristik objek wisata.

2. Partisipasi masyarakat dalam melestarikan serta membantu penyediaan jasa pariwisata serta 
akomodasi penginapan

3. Kesadaran masyarakat dalam kegiatan konservasi objek Hutan dan turut serta dalam melestarikan kawasan hutan

4. Akomodasi dan fasilitas yang disediakan menggunakan jasa masyarakat lokal terdapat regulasi yang mengatur standar kelayakan penginapan atau homestay sesuai dengan kondisi lokasi wisata

Selain penerapan Konsep Ekowisata, kegiatan pendukung wisata yang ada di objek studi pembanding juga akan diterapkan di Taman Astor. Kegiatan Wisata yang dapat diimplementasikan untuk Taman Astor adalah Panjat Tebing, Paintball dan Panahan. Ketiga kegiatan wisata tersebut dapat menggunakan sumber daya alam yang terdapat di Taman Astor yaitu Kayu Akasia. Untuk Panjat tebing sendiri Dapat menggunakan Kayu Gelondonan yang berada di Taman Astor. Untuk Flying Fox, Spider Web, dan Jembatan Gantung sulit diimplementasikan karena pohon-pohon yang terdapat pada Taman Astor cukup rapuh sehingga tidak dapat digunakan sebagai penyangga.

Analisis Kebutuhan Ruang

Pada bagian ini akan dibahas mengenai total luas yang dibutuhkan untuk Kawasan Wisata Taman Astor untuk menyediakan fasilitas. Berikut adalah kebutuhan ruang untuk Taman Astor:

Tabel 10. Program Ruang Kawasan Wisata

\begin{tabular}{|c|c|c|c|}
\hline \multirow[t]{2}{*}{ Fasilitas } & \multicolumn{2}{|l|}{ Luas } & \multirow[t]{2}{*}{ Sumber } \\
\hline & $\mathrm{M}^{2}$ & $\mathrm{Ha}$ & \\
\hline Camping Ground & 15000 & 1,5 & Eksisting \\
\hline Panggung Spot Foto & 7000 & 0,7 & Eksisting \\
\hline Taman Bermain Anak & 3000 & 0,3 & Eksisting \\
\hline Gazebo & 80 & 0,008 & $\begin{array}{l}\text { Standar Arsitektur Ernst Neufert (1994 } \\
\text { : 203) }\end{array}$ \\
\hline Pusat Informasi & 110 & 0,011 & PERMENPAR \\
\hline Ruang Bilas & 267 & 0,0267 & $\begin{array}{l}\text { Standar } \\
\text { Arsitektur Ernst } \\
\text { Neufert (1994 } \\
: \text { 203) } \\
\end{array}$ \\
\hline Toilet & 176 & 0,0176 & $\begin{array}{l}\text { Standar } \\
\text { Arsitektur Ernst } \\
\text { Neufert (1994 } \\
: \text { 203) } \\
\end{array}$ \\
\hline Warung/Restaurant & 400 & 0,04 & PERMENPAR \\
\hline Area Parkir & 475 & 0,0475 & DISHUB \\
\hline Camping Ground & 8000 & 0,8 & Penambahan Luas $8000 \mathrm{~m}^{2}$ \\
\hline Paintball & 1000 & 0,1 & jakartapaintball.com \\
\hline Panjat Tebing & 100 & 0,01 & Penulis \\
\hline Panahan & $70 \times 5 \times 4=1400$ & 0,14 & olahragapedia.com \\
\hline Sirkulasi + Jalur Motocross & 3600 & 0,36 & Penulis \\
\hline
\end{tabular}

Sumber : Olahan Penulis, 2020

Dalam Analisis Analisis Kebutuhan Ruang, Penulis membuat skema perhitungan luas dari sumber-sumber yang dapat digunakan penulis untuk menentukan kebutuhan ruang. Berikut adalah Gambaran Masterplan Perencanaan Kawasan Taman Astor. 


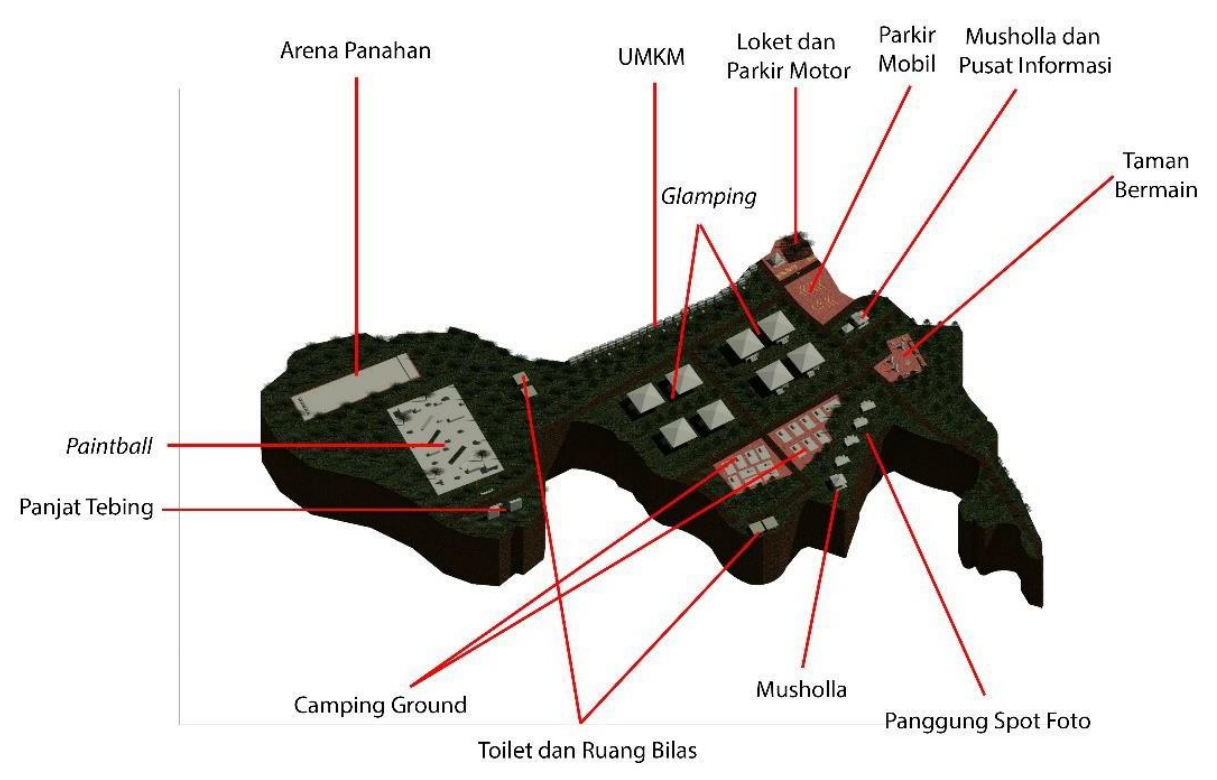

Gambar 6. Masterplan Perencanaan Kawasan Taman Astor

Sumber: Hasil Olahan Pribadi

\section{KESIMPULAN DAN SARAN}

\section{Kesimpulan}

Daya Tarik Taman Astor adalah daerah perhutanan sehingga diperlukan akomodasi yang baik. Maka dari itu penulis mengunakan 2 jenis tempat kemah yaitu Camping Ground yang mengunakan tenda dan Glamping yang mengunakan bahan yang berkualitas dan cukup luas. Penulis menyarankan agar terdapat wahana Paintball agar dapat melengkapi kegiatan wisata di Taman Astor. Taman Astor memiliki potensi untuk mengembangkan kawasannya dikarenakan masih terdapat kawasan yang belum dibangun. Berdasarkan Analisis Konsep Perencanaan Kawasan Taman Astor akan mengarah pada Konsep Ekowisata. Masterplan dibuat berdasarkan kondisi Eksisting dan perencanaan kegiatan wisata yang dapat diimplementasikan di Taman Astor.

\section{Saran}

Pemerintah dan masyarakat lokal yang berada di sekitar Taman Astor harus berkerja sama mengembangkan Taman Astor sehingga masyarakat lokal dapat berkontribusi dalam bidang kepariwisataan serta meningkatkan pendapatan masyarakat. Pengunaan Media sosial seperti Instagram, Facebook, Twitter dan sejenisnya untuk mempromosikan kawasan wisata akan lebih baik untuk memberikan informasi dan dapat meningkatkan jumlah pengunjung. Kegiatan Wisata di Taman Astor perlu diperbanyak lagi agar menambah daya Tarik.

\section{REFERENSI}

Departemen Perhubungan Darat. (1998). Pedoman Perencanaan dan Pengoperasian Fasilitas Parkir. Indonesia: Direktorat Bina Sistem Lalu Lintas dan Angkutan Kota.

Gunn. (2002). Tourism Planning: Basics, Concepts, Cases, 4th edition. New York: Routledge.

Kementrian Pariwisata. (2018). Petunjuk Operasional Pengelolaan Dana Alokasi Khusus Fisik Bidang Pariwisata. Indonesia: Sekretariat Negara.

Kodhyat, H. (1983). Sejarah Pariwisata dan Perkembangannya di Indonesia. Jakarta: PT.Gramedia Pustaka Utama. 
Muljadi, A. d. (2002). Pengertian Pariwisata Kursus Tertulis Pariwisata Tingkat Dasar. Modul I . Jakarta: Badan Pengembangan Kebudayaan dan Pariwisata Pusat Pendidikan dan Pelatihan.

Musanef. (1995). Manajemen Pariwisata di Indonesia. Jakarta: Gunung Harta.

Neufert, E. (2002). Data Arsitek Jilid II Edisi 33, Terjemahan Sunarto. Jakarta: PT. Erlangga.

Rangkuti, F. (1997). Analisis SWOT: Teknik Membedah Kasus Bisnis Reorientasi Konsep Perencanaan Strategis untuk Menghadapi Abad 21.

Suwantoro, G. (2004). Dasar-Dasar Pariwisata. Yogyakarta. 